\title{
O MOODBOARD COMO ESTÍMULO À INOVAÇÃO NO PROCESSO DE CODESIGN: ESTUDO DE CASO EM UMA STARTUP
}

Caio Marcelo Miolo de Oliveira

Universidade do Vale dos Sinos - UNISINOS

caiomarcelo.mo@gmail.com

Resumo: O design apresenta-se no presente artigo como processo próprio para atuar em organizações de diferentes segmentos que buscam inovar. Através da concepção de ferramentas próprias e da prática de trabalho em codesign com diferentes atores envolvidos no projeto, o designer busca integrar capacidades, estimular ações criativas e assim, inovar. Entre os instrumentos de design para propiciar inovação, facilitando comunicação e estímulo da criatividade dos membros de uma equipe de projeto está o moodboard. Neste contexto, o presente artigo investiga em um estudo de caso, como o moodboard pode estimular a inovação no processo de codesign realizado em uma startup. Como resultados da pesquisa tem-se uma proposta de como pode ser realizada uma atividade de construção de um moodboard; a verificação do moodboard como uma ferramenta própria para favorecer a participação de não-designers no projeto, a comunicação, o conhecimento distribuído e a sociabilidade entre membros do projeto; e por fim, própria para estimular a criatividade, aumentando assim as chances de inovar em um projeto.

Palavras-chave: moodboard, inovação, codesign, startup.

Abstract: The design is presented in this article as process itself to work in organizations of different segments seeking innovation. By designing own tools and work practice in codesign with different actors involved in the project, the designer seeks to integrate skills, stimulate creative actions and thus innovate. Among the design tools to facilitate innovation by facilitating communication and stimulating creativity of the members of a project team is the moodboard. In this context, this paper investigates on a case study, as the moodboard can stimulate innovation in the codesign process carried in a startup. The research results has a proposal how it can be done a moodboard construction activity; checking the moodboard as a proper tool to encourage the participation of non-designer in the design, communication, distributed knowledge and sociability among project members; and finally own to stimulate creativity, thus increasing the possibilities of innovation in a project.

Keywords: moodboard, innovation, codesign, startup 


\section{INTRODUÇÃO}

As pesquisas sobre inovação são recorrentes e mostram-se em ascensão em diferentes disciplinas e áreas de conhecimento. Conforme verificado na base de dados

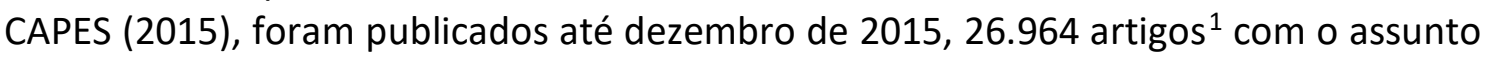
relacionado à inovação; deste total de artigo computados, 12.906 foram publicados nos últimos cinco anos ${ }^{2}$. Observa-se portanto um aumento considerável do número de artigos sobre este assunto, tendo em vista que quase a metade do total de artigos foi publicada nos últimos cinco anos.

Nas organizações também é verificada a constante busca por formas de inovar para diferenciar-se na concorrência mercadológica ou mesmo sobreviver à esta. Dentre estas organizações que buscam inovar estão as startups. Startups são empresas em fases iniciais de desenvolvimento (HYYTINE et al., 2015), que possuem a inovação como estratégia de negócios, tendo sua base técnica de produção sujeita a mudanças frequentes, devido aos esforços dedicados à pesquisa e desenvolvimento tecnológico (FINEP, 2015). Por serem inovadoras e estarem em desenvolvimento inicial, Gitahy (2010) afirma que elas lançam-se no mercado em condições de grandes incertezas, sem ter garantias se as inovações de seus serviços/produtos propostos sortirão efeitos positivos no mercado, e por conseguinte, se serão sustentáveis a longo prazo.

Trabalhando também diretamente com finalidade de inovar está o design. 0 design possui métodos e ferramentas próprios para estímulo e gerenciamento de inovações, que portanto poderiam ser exploradas pelas startups, a fim de fortalecer suas chances de sucesso no mercado. Segundo Borja de Mozota (2003) a área do design não é mais visto apenas como o resultado final de um projeto, relacionado à forma, função e venda, mas como um processo criativo de gestão de ideias, de inovação de pesquisa, de integração das capacidades internas da organização.

Dentre as estratégias do design para facilitar o processo criativo trazido por Borja de Mozota, está o codesign. O codesign compreende o desenvolvimento projetual do designer em colaboração com diferentes atores não-designer vindos de disciplinas, experiências e conhecimentos distintos, pensando de forma sistêmica (MERONI, 2008; ZURLO, 2010). Como formas para trabalhar em codesign o designer pode conceber ou adaptar diferentes ferramentas para facilitar a comunicação entre os participantes, apoiar a visualização das estratégias, compreensão das interações, síntese de problemas, testar ideias e mesmo estimular a criatividade (CANTÚ, 2012). Neste ponto é importante destacar que existem diferentes instrumentos de design, vindas de diferentes escolas de design, ou mesmo de outras áreas de conhecimento, que são mais adequadas para cada uma dessas finalidades exemplificadas por Cantú (2012).

Como instrumento para propiciar inovação, facilitando comunicação e estímulo da criatividade dos participantes em um projeto de codesign está o moodboard. 0 moodboard é corriqueiramente identificado por ser um instrumento especificamente de visualização de uma ideia já concebida ou o dos estilos de vida dos usuários, através da composição de diferentes fotos, imagens, texturas, palavras-chave e cores que sintetizem a atmosfera que se quer representar (MERONI, 2007; MERONI e

\footnotetext{
${ }^{1}$ Pesquisa realizada utilizando o filtro de pesquisa "periódicos revisados por pares" e com a palavra inovação no filtro "assunto".

${ }^{2}$ De dezembro de 2010 à dezembro de 2015.
} 
SANGIORGI, 2011; BEST, 2006). No entanto, o moodboard também pode ser utilizado como estímulo à inovação, conforme referido por McDonagh e Denton (2005, p.36): "um visual, podendo ser multi-sensorial [...] o qual pode ter valor em auxiliar a comunicação e a inspiração durante todo o processo de concepção ".

Neste contexto, o presente artigo propõe investigar, em um estudo de caso, como o moodboard pode estimular a inovação no processo de codesign realizado em uma empresa que busca inovar. E nesse âmbito, propor o moodboard como um instrumento que habilite a participação de não-designer em um processo de inovação. Como unidade de análise está a Luneta ${ }^{3}$, startup constituída participante de um workshop de inovação organizado por professor e aluno membros do grupo de pesquisa Design Estratégico e Cultura de Projeto do curso de Design de uma universidade. $\mathrm{O}$ autor deste artigo participou do workshop junto à empresa Luneta realizando o papel de designer.

Com base no workshop e no referencial teórico explorado, ao final do estudo, busca-se apresentar uma reflexão sobre como o moodboard pode estimular a inovação em processo de codesign realizado em uma startup.

\section{INOVAÇÃO E DESIGN}

Antes de reconhecer como o design trabalha para estimular a inovação organizacional, mostra-se necessário explicitar qual a definição de inovação utilizada no presente artigo. Inovação é definida pelo diretor da Escola Politécnica de Milão, Roberto Verganti (2005), por meio de três características: ser uma novidade, ter maior valor agregado e por ser aplicável ao dia a dia dos consumidores, ou seja, é necessário que a inovação seja colocada em prática. $O$ autor compreende ainda que a inovação deve construir novos significados (VERGNATI, 2008).

Para criar produtos e serviços inovadores através do design destacam-se dois atributos abordados por Borja de Mozota (2006) que podem favorecer o desenvolvimento de inovações: design como integrador e design como transformador. Design como integrador implica em administrar o processo de inovação na organização, atuando como coordenador de funções, motivando equipes interdisciplinares, melhorando a comunicação entre elas, estimulando relacionamentos pautados no compartilhamento de ideias, tornando mais fértil o processo de inovação na organização (BORJA DE MOZOTA, 2003; 2006). A autora se refere ainda sobre a integração com o meio externo à organização (clientes, fornecedores, sociedade, entre outros) como forma de estimular a inovação.

O outro atributo trazido pela autora supracitada que acaba por estimular a inovação é o design como transformador, com intuito de criação de novas oportunidades de inovação, prevendo tendências, compreendendo necessidades e desejos dos usuários, integrando a área design e tecnologia, possibilitando assim a concepção de inovações. O design atua com a responsabilidade de aumentar a capacidade da organização em lidar com mudanças, a estarem abertas para inovações, contribuindo assim para um maior aprendizado dentro delas (BORJA DE MOZOTA, 2003).

Nesse âmbito, para que o designer possa atuar em uma organização como integrador e transformador para favorecer inovações, mostra-se necessário que ele

${ }^{3}$ Nome fictício. 
desenvolva plataformas e ferramentas necessárias para incentivar a participação criativa das pessoas envolvidas (COTTAM e LEADBEATER, 2004). Como estratégia para tal está o codesign.

\subsection{Codesign}

Diferente de cocriação, "um termo amplo que se refere a qualquer ato de criatividade coletiva, ou seja, a criatividade que é compartilhada por duas ou mais pessoas", o codesign refere-se ao processo de design em que designers trabalham junto com não-designers, orientando-os e treinado-os para desenvolver algum determinado projeto em conjunto (SANDERS e STAPPERS, 2008, p.6). Os não-designers podem ser atores vindos de disciplinas, experiências e conhecimentos distintos, pensando de forma sistêmica (MERONI, 2008; ZURLO, 2010), sejam eles usuários, produtores, funcionários, fornecedores, parceiros, entre outros, acabam formando uma plataforma de interação (MANZINI, 2011). Ao participarem colaborativamente do processo projetual, seja na concepção, testes, momentos de decisão, os não-designers podem adquirir, em parte, as capacidades de pensar e agir do design, de modo a apropriarem-se do processo projetual, utilizando-as em outras situações nãoprojetuais (MERONI, 2008).

$\mathrm{Na}$ área de design colaborativo (mesmo sentido de codesign), Alexiou (2010) identifica quatro dimensões comuns em trabalhos de codesign: de que o conhecimento é distribuído; que trata-se de um processo social; que a criatividade é um atributo coletivo; e a importância da comunicação.

A primeira dimensão referida por Alexiou (2010), caracteriza que o conhecimento existente em um processo de codesign é distribuído entre os membros do projeto, não pertencente aos domínios do designer apenas, mas pela rede social de conhecimento, que inclui agentes humanos e artificiais, que compartilham conhecimento para resolver determinado problemas. Nesse sentido, o conhecimento distribuído no codesign não é resultado da soma dos saberes individuais, mas das combinações, aprendizagens e interações complexas desenvolvidas entre os saberes dos atores envolvidos.

A segunda dimensão trazida pela autora, considera o codesign como um processo social, que envolve interdependências complexas de relações, negociações, persuasões, compromissos, decisões individuais e até mesmo conflitos, que também podem ser válidos ao processo projetual, pois para resolvê-los necessita de esforços colaborativos, para que se chegue a um alinhamento de compreensão, obtendo um senso comum do grupo.

A terceira dimensão do codesign refere-se à criatividade, que é verificada como um atributo coletivo e que todos possuem, designers e não-designers. Tanto a criatividade individual e coletiva baseiam-se em conhecimento coletivo, que é o desenvolvido através das interações mediadas entre as pessoas, ferramentas, técnicas e tecnologias (ALEXIOU, 2010). A quarta e última dimensão ratifica o codesign como um processo de comunicação, que facilita a detecção e compreensão dos problemas e conflitos, que podem ser mediadas por conversas ou através de formas indiretas, como desenhos. Estes que cognitivamente podem ser apresentados como mecanismos para o desenvolvimento da atividade colaborativa e de coordenação (ALEXIOU, 2010). 
No âmbito do design são estudados e explorados diferentes instrumentos que podem ser utilizados de forma associada para facilitar processos de codesign com nãodesigners. Dentre eles está a concepção de moodboards.

\subsection{Moodboard}

O moodboard é um instrumento de design que pode ser utilizado para diferentes finalidades. Corriqueiramente ele é utilizado como um painel de visualização sintética sobre uma atmosfera característica da situação observada, usando diferentes imagens (MERONI, 2007). Além de imagens, pode-se utilizar texturas, palavras-chave e cores, que auxiliem a transmitir o contextos, o sentido ou estilo de um produto ou serviço proposto (MERONI e SANGIORGI, 2011). Segundo as autoras, "um moodboard funciona como uma analogia, não tão uma metáfora: portanto, o significado e a importância das diferentes imagens devem convergir e ser coerentes com a finalidade da comunicação e a fenomenologia do serviço" (p.252), ou produto projetado.

Além de sintetizar a atmosfera de um contexto, serviço ou produto já planejados, o moodboard pode "auxiliar a comunicação e inspiração durante todo o processo de concepção" (MCDONAGH e DENTON, 2005, p.36). Caracterizando assim as duas principais funções do moodboard: a primeira função de inspiração, tanto para um designer individual, quanto para uma equipe; e a segunda função de comunicação, apoiando os diálogos internos entre a equipe de projeto. Esta segunda, envolve ainda a habilidade de conseguir comunicar de forma mais tangível, sentidos abstratos aos não-designers, proporcionando um canal de comunicação para além da escrita e do diálogo" (COSTA, et at., 2003); possibilitando assim, que se consiga obter uma visão compartilhada do projeto (MCDONAGH e DENTON, 2005). Entende-se neste sentido, que mais do que tornar mais tangíveis as ideias de um projeto aos não-designers, o moodboard pode ser um instrumento para empoderar não-designers a participarem de um projeto de codesign; questão que deseja-se verificar no presente artigo.

Nesse contexto, para conseguir utilizar o moodboard como instrumento de inspiração, comunicação e proporcionar uma visão compartilhada do projeto, Garner e McDonagh identificam a importância saber utilizar do pensamento lateral, proposto por Edward Debono (1970, apud, GARNER e MCDONAGH, 2001, p.58):

o pensamento lateral está [...] preocupado com o sair das prisões de conceitos de velhas ideias. Isto leva a mudanças de atitude e abordagem; para olhar de uma maneira diferente para as coisas que sempre foram olhadas da mesma maneira. Libertação de ideias e a estimulação de novas são aspectos gêmeos do pensamento lateral.

Sendo assim, as diferentes imagens, texturas, palavras-chave ou cores que compõem um moodboard, precisam ser interpretadas de diferentes formas que não sejam exatamente àquelas que estão retratadas. Por exemplo, a imagem de um carro pode representar mais que o objeto carro, mas também, modernidade, poder, velocidade, pressa, entre outras características.

A partir dessas condições, Garner e McDonagh (2001) logo qualificam o moodboard como uma ferramenta pivô de um projeto bem sucedido, porém não se pode ter garantia disto, visto que o uso adequado da ferramenta (conseguir 
interpretar imagens, utilizar o pensamento lateral) faz imensa diferença na condução de uma proposta relevante, ágil e inovadora.

Por conseguinte, para se explorar as qualidades apresentadas do moodboard como estímulo à inovação, apresenta-se a seguir como foi o processo de construção de um moodboard em uma atividade de codesign realizada com uma startup, que constitui a unidade de análise do presente artigo.

\section{MÉTODO DE PESQUISA}

Com intuito de responder ao objetivo do presente artigo, sobre como o moodboard pode estimular a inovação no processo de codesign, realizou-se um estudo de caso. A finalidade do estudo de caso é tentar esclarecer uma decisão ou um conjunto de decisões, os motivos pelos quais foram implementadas e seus resultados (GIL, 2009). Portanto, o estudo de caso mostra-se pertinente ao objetivo da pesquisa, pois o processo realizado envolve tomadas de decisões e os resultados alcançados também são relevantes à presente pesquisa, pois fornecerão insumos para discussão sobre o objetivo do presente artigo.

A análise foi desenvolvida a partir da triangulação de dados: dos dados secundários (bibliográficos), os dados primários de observação do pesquisador sobre o processo e as respostas à entrevista realizada com os sócios da startup. A partir do estudo foi possível identificar diretrizes sobre como a construção do moodboard pode estimular a inovação no processo de codesign realizado em uma startup.

\subsection{Unidade de análise}

A unidade de análise do presente artigo trata-se da startup "Luneta", participante de um workshop de inovação organizado por professor e aluno membros do grupo de pesquisa "Design Estratégico e Cultura de Projeto" do curso de Design de uma universidade. O autor deste artigo participou do workshop junto à startup realizando o papel de designer, estimulando o codesign. Participaram do workshop dois dos três sócios da Luneta.

Os dados sobre a startup foram coletados através de entrevista feita previamente com um dos sócios da Luneta. A Luneta, constituída por três sócios e duas estagiárias possui até o momento apenas um produto lançado, um aparelho inovador que gela bebidas através de rotação destas sobre uma fonte fria, diminuindo o tempo de processo de resfriamento para cerca de dois minutos.

A Luneta não possui ainda processos formalizados para geração de inovações. O que eles costumam fazer em alguns momentos são os brainstormings ${ }^{4}$ para estimular geração de ideias. E como forma de captar inspirações ela participa de alguns eventos que proporcionam conversas com outras empresas e visualização do que está sendo feito no mercado. Quando questionados se a empresa possui vínculos com outras startups, foi explicado que ainda não, pois não há a cultura de integração entre estas startups.

\footnotetext{
${ }^{4}$ Brainstorming é uma "tempestade de ideias", uma técnica que tem como objetivo gerar um grande volume de alternativas para solução ou compreensão de um problema de projeto (BORBA, et al. 2013)
} 


\subsection{Descrição sobre a construção do moodboard}

As atividades projetuais ocorridas durantes o workshop perdurou por quatro encontros, ocorridos no endereço da startup, nos dias 18, 19 e 20 de novembro de 2015 e dia 10 de dezembro de 2015.

No primeiro dia de workshop foi solicitado pelos organizadores que o designer (autor do presente artigo) e os dois sócios da Luneta projetassem produtos/serviços inovadores. Para tanto, o primeiro encontro foi destinado para captação de sinais, ou seja, para inspiração e pesquisa do que se poderia ser projetado de inovação. 0 segundo encontro destinou-se à criar, o terceiro à testar e o último era livre para que os participantes fizessem o que acreditassem ser mais adequado para a efetivação do projeto. No presente artigo será explorado como foi o primeiro encontro, pois foi neste que se desenvolveu o moodboard.

Para facilitar o processo de codesign proposto, os organizadores do workshop ofereceram cartas que continham explicações sobre alguns instrumentos de design, no entanto foi dito que era possível utilizar outros instrumentos que desejassem, que não estivessem presentes nas cartas. Assim, no primeiro encontro, para iniciar o processo de captação de sinais, o designer (pesquisador) sugeriu a construção de um moodboard e outros instrumentos que pudessem ser feitos no pouco tempo disponível, cerca de uma hora e meia. Os sócios da Luneta concordaram em realizar inicialmente o moodboard. A partir desta decisão do grupo, o designer explicou aos dois sócios da Luneta como poderia ser feito o moodboard: que poderiam inicialmente buscar imagens inspiradoras nas revistas disponíveis e depois discutir sobre cada uma delas, de modo que cada um explicasse o que o inspirou na imagem. Ambos os sócios da Luneta compreenderam e aprovaram a ideia.

Assim, ficou estipulado que inicialmente seriam buscadas as imagens e colocadas sobre a cartolina disponível e depois disso, destinar-se-ia um tempo para conversar sobre as imagens, e que cada participante poderia explicar o que cada imagem o fez pensar. Após esta exlicação, o designer e os dois sócios começaram a pesquisas por imagens e colocá-las sobre a cartolina.

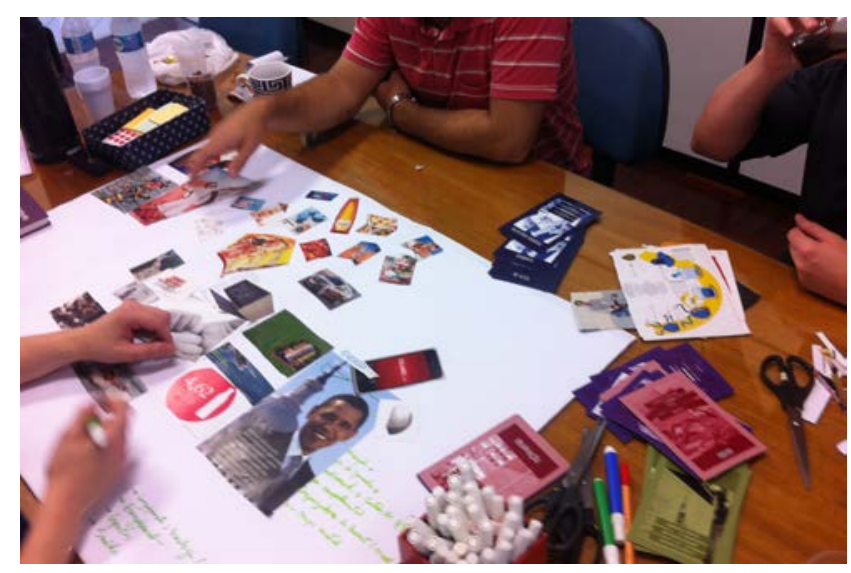

Figura 1 - Construção do moodboard.

Fonte: material de campo.

No momento destinado à discussão sobre as imagens, um dos sócios da Luneta explicou que não havia compreendido que as imagens poderiam ser interpretadas e que só havia coletado imagens de produtos ou serviços que acreditava serem interessantes. No entanto o designer explicou que não teria problema, que poderíam 
conversar sobre as imagens que ele havia buscado, pois poderia inspirar ideias dos demais.

Após coletadas as imagens, o designer começou a estimular conversas sobre as imagens, explicando inicialmente o que cada imagem coletada o fez lembrar ou quais ideias poderiam surgir a partir delas. Durante as explicações, os dois sócios falavam sobre as imagens coletadas pelo designer e sugeriam algumas outras ideias e percepções. Na sequência cada um dos sócios explicou suas imagens e novamente surgiram novas ideias sobre as referências coletadas.

Por fim, após todos explicarem suas imagens, o designer sugeriu que as imagens fossem agrupadas por semelhança, para facilitar a escolha por qual tipo de serviço/produto projetar. Foram então discutidos quais eram os possíveis grupos de imagens, chegando-se à três grupos de imagens: o primeiro de imagens relacionadas à saúde; o segundo ligado ao cotidiano e o terceiro sobre contexto social-políticoambiental.

Após esta organização de imagens, o designer e os sócios da Luneta decidiram escolher para qual desses três assuntos projetariam o novo produto/serviço. Escolheuse então que a inovação a ser criada seria destinada ao tema "cotidiano". Após esta decisão iniciou-se um brainstorming inspirado principalmente pelas imagens do grupo "cotidiano". O designer anotava as ideias que surgiam no espaço em branco disponível na própria cartolina do moodboard.

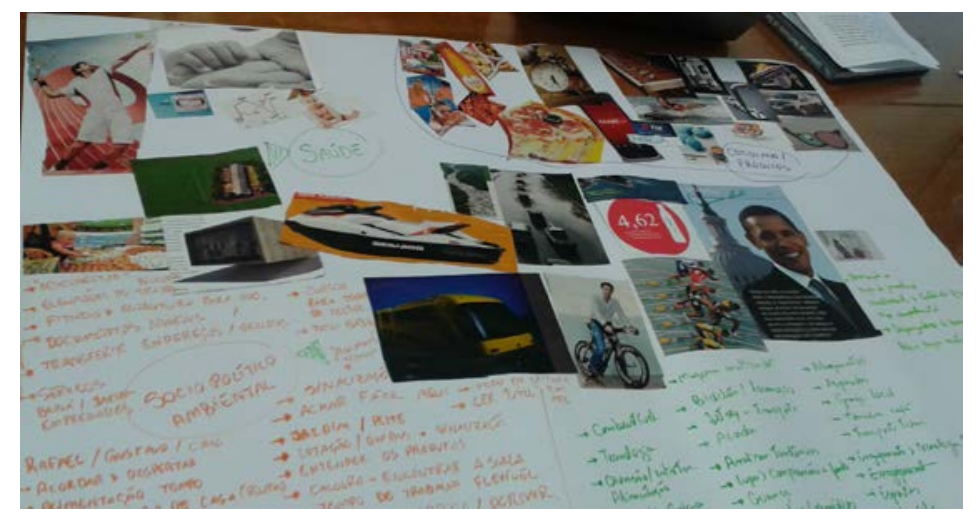

Figura 2-0 moodboard e as ideias surgidas a partir dele.

Fonte: material de campo.

Após a realização do brainstorming feita com base no moodboard, o grupo separou algumas ideias mais pertinentes que poderiam ser melhor criadas e testadas nos encontros seguintes. Encerrou-se assim o primeiro encontro destinado à captação de sinais e de inspiração.

No encontro seguinte, dia 19/11/2015, para facilitar a escolha de qual ideia seria prototipada, o designer e os sócios da Luneta escolheram quatro das ideias criadas no dia anterior e entrevistou pessoas que trabalham no mesmo núcleo de startups onde residem, para descobrir quais ideias poderiam ser mais pertinentes de ser implementadas. A partir das compreensões e respostas das pessoas entrevistas, optou-se por uma das ideias. A ideia escolhida foi melhor formulada e posteriormente prototipada no terceiro encontro. Embora a ideia escolhida tenha sido modificada e melhor desenvolvida durante as conversas realizadas no processo, esta foi originada de sinais captados no moodboard. 


\subsection{Coleta de dados}

Para compreender como o moodboard estimulou a inovação no processo de codesign, realizou-se uma entrevista com os participantes ao final do primeiro encontro, no dia 18/11/2015. As perguntas foram realizadas a partir de um questionário semi-estruturado com base no processo realizado. As perguntas foram as seguintes:

1. Como o moodboard contribui para a captação de sinais e inspirações?

2. Quais foram as dificuldades encontradas na construção do moodboard?

3. O moodboard serviu como estímulo à inovação no processo de codesign?

Quando questionados como o moodboard contribuiu para a captação de sinais e inspirações, os sócios da Luneta comentaram que foi um instrumento válido para abrir o pensamento, favorecer a percepção das imagens de modo mais amplo, pois geralmente eles não interpretam as imagens vistas em uma revista ou em outras fontes, como digitais. Outra qualidade percebida do moodboard foi seu potencial em captar inspirações em pouco tempo, através de associações entre as imagens coletadas e vivências pessoais.

O moodboard também foi apontado como uma forma de possibilitar colaborações entre a equipe, visto que no momento de discussão sobre as imagens, cada um pôde contribuir com a ideia ou percepção do outro. E nesse sentido, o instrumento tornou acessível a combinação das ideias e inspirações, que se não estivessem ali visíveis, talvez não fossem mencionadas, relacionadas entre si e até mesmo aprimoradas.

Sobre as dificuldades encontradas no processo de construção do moodboard, os sócios da Luneta comentaram que talvez os temas das revistas utilizadas na construção do moodboard possa ter direcionado um pouco o tipo de inspirações encontradas. No entanto, logo eles comentaram que qualquer busca que eles fizessem na internet também poderia ser limitante, seja pelo tema que eles buscassem ou qual plataforma estivessem utilizando.

Por fim, quando perguntado se eles utilizariam a construção do moodboard em outros projetos como forma de captar sinais e estimular a inovação, os sócios responderam que sim. Um deles afirmou não gostar tanto da ideia de precisar recortar e colar papéis, no entanto, achou válido o instrumento. O outro sócio respondeu que sim, que poderiam começar a utilizar o moodboard, mas não tem certeza se ocorreria de modo adequado sem a presença do designer junto no processo, pois sua participação na atividade foi fundamental para orientar o processo.

\section{ANÁLISE SOBRE A CONTRUÇÃO DO MOODBOARD COMO ESTÍMULO À INOVAÇÃO NO PROCESSO DE CODESIGN}

A partir da triangulação dos dados desta pesquisa revelou-se que a construção do moodboard foi percebida como um instrumento pertinente para atividades de codesign, potencializando as qualidades apontadas por Alexiou (2010), McDonagh e Denton (2005): propiciou o conhecimento distribuído, visto que permitiu que os participantes expusessem suas percepções e os demais pudessem contribuir com o que foi comentado; a sociabilidade, proporcionando que o designer e os sócios da Luneta pudessem estabelecer uma relação social, através das trocas de ideias, e nesse 
sentido; a comunicação, pois as associações e interpretações das imagens foram princípios para a comunicação entre todos; e finalmente, criatividade, pois a construção do moodboard foi o que estimulou os participantes a criarem soluções, problematizarem e gerarem conceitos projetuais.

O estudo de caso realizado também revelou as qualidades do moodboard como um instrumento com qualidades maiores que representar ou sintetizar conceitos ou sentidos de um projeto, mas como forma de habilitar os não-designers a criarem e favorecer a comunicação de sentidos abstratos de forma mais tangível, conforme o que Costa, et al. (2003) identificam. E nesse sentido, constatou-se o favorecimento de uma visão compartilhada dos problemas que poderiam ser solucionados ou de novas oportunidades de projeto (MCDONAGH e DENTON, 2005).

Em relação ao propósito do presente artigo, de propor o moodboard como estímulo à inovação em um processo de codesign, não pôde-se verificar se de fato surgirão produtos/serviços inovadores, pois o projeto concebido ao final do workshop, a partir de inspirações captadas no moodboard ainda não foi continuado e implementado. No entanto, pôde-se verificar que a construção do moodboard foi o que gerou discussões, comunicação, relacionamentos, compartilhamento de ideias, a visualização de tendências, de possíveis oportunidades, gerações de insights de proteto. E nesse sentido, revelou questões levantadas por Borja de Mozota (2003; 2006) que são importantes para a gerações de inovações em um processo de design, caracterizando potenciais do design como integrador e transformador, gerando integração entre os membros do projeto e favorecendo inovações.

Quanto a adequação do moodboard aos processos de inovação da startup, foi reconhecido pelos sócios da Luneta como um instrumento adequado, interessante de ser aplicado em curto espaço de tempo, porém, de início poderia haver acompanhamento de designer, para que a equipe da startup pudesse sentir mais segurança e conseguir apropriar-se do processo, conforme indicado por Meroni (2008) na fundamentação teórica.

Por fim, é importante destacar que através do estudo de caso realizado, pôdese verificar que a construção do moodboard não garante o estímulo à inovação em processos de codesign, mas pode ser um meio e uma parte deste processo, pertinente de se utilizar. E nesse sentido, compreendendo parte do processo, a construção do moodboard pode ser feita em colaboração com outros instrumentos, como ocorreu no presente estudo, que após ser feito o moodboard, a equipe realizou um brainstorming, entrevistou pessoas para coletar percepções sobre as ideias, para posteriormente prototipar a ideia escolhida pelo grupo.

\section{CONCLUSÃO}

A partir da pesquisa realizada, observou-se o moodboard como uma estratégica mais potente que visualização e síntese de conceitos, mas como forma de estimular a comunicação, criatividade, conhecimento distribuído, sociabilidade, e como forma de habilitar a participação de não-designers em um processo de codesign. O instrumento também foi percebido como forma de ampliar a visão dos membros da startup, que notaram a relevância em interpretar as imagens, que elas podem representar mais do que seu sentido primário, "literal". Nesse sentido, ao habilitar tais qualidades mencionadas, o design pôde ser verificado como uma abordagem projetual pertinente em processos de inovação em startups. 
Como estudos futuros, sugere-se acompanhar o processos de codesign com uso do moodboard até sua implementação, para reconhecimento das evoluções projetuais e se o instrumento estimulou de fato a concepção de um produto/serviço inovador. $E$ por fim, sugere-se estudar instrumentos de decisão a serem utilizadas no momento de escolha de quais ideias captadas da construção do moodboard podem ser mais interessantes de ser exploradas, pois, as técnicas utilizadas neste estudo de caso foram empíricas, envolvendo votação das ideias e após isto entrevistas com diferentes pessoas. Estas técnicas podem ter sido pertinentes, porém acredita-se que mereça melhor aprofundamento teórico e prático.

\section{REFERÊNCIAS}

ALEXIOU, Katerina. Complexity and coordination in collaborative design. In: ALEXIOU, Katerina; JOHSON, Jeffrey; ZAMENOPOULOS, Theodore (ed.). Embracing Complexity in design. 1. Ed. New York: Routledge, 2010. p.73-93. 2010.

BEST, Kathryn. Design Management: Managing Design Strategy, Process and Implementation. London: AVA Publishing SA, 2006.

BORBA, Gustavo Severo de; ROSA, Mirela; FREIRE, Karine. S.O.S Criativo: Kit para explorar, criar e testar ideias. 2013.

BORJA DE MOZOTA, Brigitte. Design management: using design to build brand value and corporate innovation. New York: Allworth Press, 2003.

BORJA DE MOZOTA, Brigitte. The Four Power of Design: A Value Model in Design Management. Design Management Review Vol.17 No. 2. New, 2006.

CANTÚ, Daria. Ideas Sharing Lab. Community Centred Design for Multifuncional and Collaborative Food Services. Doctoral Thesis, Politécnico Di Milano, FEB. 2012.

CAPES. Disponível em: < http://www.periodicos.capes.gov.br >. Acesso em 5 dez. 2015.

COSTA, A I A, SCHOOLMEESTER, D; DEKKER, M; JONGEN, W M F. Exploring the use of consumer collages in product design Trends in Food Science and Technology. Vol 14 pp 17-31, 2003.

COTTAM, H.; LEADBEATER C. Health: Co-creating Services. London, Design Council, 2004.

FINEP. Glossário. 2015. Disponível em: < http://www.finep.gov.br/biblioteca/glossario >. Acesso em 5 dez. 2015.

GARNER, S; MCDONAGH-PHILP, D. Problem Interpretation and Resolution via Visual Stimuli: The Use of 'Mood Boards' in Design Education. In:The Journal of Art and Design Education, p. 57-64, 2001.

GIL, Antonio Carlos. Métodos e técnicas de pesquisa social. 5. ed. São Paulo: Atlas, 2009.

GITAHY, Yuri. O que é uma startup? 2010. Disponível: < http://exame.abril.com.br/pme/noticias/o-que-e-uma-startup >. Acesso em 5 dez. 2015. 
HYYTINEN, Ari; PAJARINEN, Mika; ROUVINEN, Petri. Does innovativeness reduce startup survival rates? Journal of Businness Venturing 30, 564-581, 2015.

MANZINI, E. In: MERONI, Anna; SANGIORGI, Daniela. Design for services. Gower Publishing, 2011.

MCDONAGH, D., \& DENTON, H. Exploring the degree to which individual students share a common perception of specific mood boards: Observations relating to teaching, learning and team-based design. Design Studies, 26(1), 35-53, 2005.

MERONI, Anna. (ed.). Creative Communities. People Inventing Sustainable Ways of Living. Milan: Edizioni Polidesign, 2007.

MERONI, Anna. Strategic design: where are we now? Reflection around the foundations of a recent discipline. Strategic Design Research Journal, v.1, n.1, Dec 1, p.31-38, 2008.

MERONI, Anna; SANGIORGI, Daniela. Design for services. Gower Publishing, 2011.

SANDERS, Elizabeth B-N; STAPPERS, Pieter Jan. Co-creation and the new landscapes of design. CoDesign, v.4, n.1, p-5-18, mar. 2008. Disponível em:

<http://www.tandfonline.com/doi/abs/10.1080/15710880701875068>. Acesso em 10jun. 2015.

VERGANTI, Roberto. Sete Perguntas: "Não existe manual de inovação", declara Roberto Verganti. Editora Unicamp, 2005. Disponível em: < http://www.exame.abril.com.br/revista-exame/edicoes/1017 > . Acesso em 8 dez. 2015.

VERGANTI, Roberto. Design, Meanings and Radical Innovation: a metamodel and a research agenda. The Journal of Product Innovation Managements, v.25, p.436-456. 2008.

ZURLO, Francesco. Design Strategico. In: XXI Secolo, vol. IV, Gli spazi e le arti. Roma: Enciclopedia Treccani, 2010. 